\title{
Promoting Student Collaboration in a Detracked, Heterogeneous Secondary Mathematics Classroom
}

\author{
Megan Staples \\ University of Connecticut -Storrs, megan.staples@uconn.edu
}

Follow this and additional works at: https://opencommons.uconn.edu/merg_docs

Part of the Curriculum and Instruction Commons, Science and Mathematics Education Commons, and the Teacher Education and Professional Development Commons

\section{Recommended Citation}

Staples, Megan, "Promoting Student Collaboration in a Detracked, Heterogeneous Secondary Mathematics Classroom" (2008). CRME Publications. 2.

https://opencommons.uconn.edu/merg_docs/2 
Promoting Student Collaboration in a Detracked, Heterogeneous Secondary Mathematics Classroom

\author{
Megan E. Staples \\ University of Connecticut, Storrs \\ megan.staples@uconn.edu
}

The original publication is available at www.springerlink.com. The full citation is as follows:

Staples, M. E. (2008). Promoting student collaboration in a detracked, heterogeneous secondary mathematics classroom. Journal of Mathematics Teacher Education, 11(5), 349-371.

An earlier version of this paper was presented at the Annual Meeting of the American Educational Research Association, Chicago, 2007 as part of the Tracking and Detracking SIG session Teaching, Learning, and Other Outcomes in Tracked and Detracked Environments. 
Abstract:

Detracking and heterogeneous groupwork are two educational practices that have been shown to have promise for affording all students needed learning opportunities to develop mathematical proficiency. However, teachers face significant pedagogical challenges in organizing productive groupwork in these settings. This study offers an analysis of one teacher's role in creating a classroom system that supported student collaboration within groups in a detracked, heterogeneous geometry classroom. The analysis focuses on four categories of the teacher's work that created a set of affordances to support within group collaborative practices and links the teacher's work with principles of complex systems. 
Promoting collaboration among students has become an important focus of instruction aligned with mathematics reform efforts (National Council of Teachers of Mathematics [NCTM], 1989, 1991, 2000; National Research Council, 2001). From a cognitive perspective, collaboration can promote conceptual understanding as students have the opportunity to share their thinking, consider alternate conceptions and discrepancies, and make sense of various representations or abstractions (Schwartz, 1999). From a sociocultural perspective, collaboration engages students in core practices of mathematics such as justifying, representing, and reconciling (Ball \& Bass, 2000). Through their participation in these practices students become increasingly proficient with mathematics.

One format used extensively to promote collaboration is groupwork. Although ample research demonstrates the potential for positive outcomes of groupwork in classrooms (e.g., Cohen, 1994a; Lou, Abrami, Spence, Poulsen, Chambers, \& d'Apollonia, 1996; Webb, 1991), teachers find organizing productive student collaboration within this participation structure a significant pedagogical challenge (Cohen, Brody, \& Sapon-Shevin, 2004). The complexity of organizing collaborative interactions may be even greater in more heterogeneous settings. All classrooms are heterogeneous to a degree, whether in a tracked or detracked setting. However, in detracked settings, there may be more dimensions of heterogeneity such as students' prior attainment and experiences with mathematics, levels of academic success and school affiliation, and proficiency with study skills. Social dynamics are also increasingly complex. Unequal participation or marginalization of some students is a threat to effective groupwork.

An assumption motivating this study is that there is a need for detailed analyses of effective implementation of groupwork in heterogeneous classrooms, particularly on the high school level, and a need for ways to better understand the complexities of classrooms that 
support and promote student-student collaboration. In this paper, I report findings from a case study of one high school geometry class in a detracked mathematics program where groupwork was the primary instructional format. The purpose of this study was to understand how the teacher supported and sustained students' participation in collaborative interactions as they worked in heterogeneous groups on open, conceptually focused problems. To position this study, I briefly review some of the literature on teaching in detracked, heterogeneous settings. I also discuss aspects of complexity science, as this framework became important in helping me make sense of this mathematics classroom. In particular, it must be recognized that student practices, including collaboration, are emergent with respect to the classroom system and teacher's pedagogical strategies. Teachers cannot prescribe collaborative interaction, but can organize the classroom system to promote and occasion opportunities for collaboration.

\section{Background Literature and Conceptual Framework}

\section{Tracking and Detracking}

Tracking is a school organizational structure commonly used in the United States (Carey, Farris, \& Carpenter, 1994), whereby students are grouped for course taking based on perceived ability, although other factors such as parent or student self-selection may also play a role. In some cases, students are assigned to a level, or stream, (e.g., honors, college preparatory, general) and take all their courses within that level. In other cases, students are grouped by ability by subject or by course. For example, a school might offer several levels of algebra (e.g., honors, advanced, regular, basic), and a student might take basic mathematics while taking advanced English. These grouping practices presumably are designed to optimally support and challenge a group of like-minded, similarly capable students. These practices are so common in 
secondary schools in the United States that the term detracked is used to indicate a lack of this grouping structure.

This organizational practice, while seemingly reasonable in its conceptualization, has been shown to lead to some negative outcomes for students both in terms of student achievement and self concept. The outcomes can be linked to the students' classroom learning opportunities which are influenced by the quality and rigor of curricular materials (e.g., Boaler, 2002; Gamoran, 1993; Linchevski \& Kutscher, 1998; Oakes, 1985), teacher expectations of students (Guitiérrez, 1996; Oakes, 1990), and students' views of themselves based on their placement within a tracked system (Perry, 2007).

The potential benefits of detracking are also well documented (e.g., Boaler, 2002; Boaler \& Staples, in press; Burris, Heubert, \& Levin, 2006). Detracking by itself, however, may not alleviate the negative outcomes associated with tracking as there are mechanisms by which students of different initial achievement levels can be offered different learning opportunities within the same classroom. As Cohen (1997) notes, "Social systems in heterogeneous classrooms have the potential to recreate a new status order that reflects, at least in part, the old status order of tracking and ability grouping" (p. 7). For example, the curricular materials used in heterogeneous settings may not allow all students access to a rich curriculum. Similarly, a teacher may hold different expectations of different students. Thus, the potential benefits of detracking can only be realized at the classroom level. As teachers work in detracked settings, they face significant challenges in organizing effective instruction for their students. Detracked programs on the high school level are uncommon, particularly in mathematics, and we have few models of successful implementation.

Promoting Collaboration: The Use of Groupwork 
One instructional strategy that has been implicated as a promising format for supporting student participation and learning in heterogeneous classes is groupwork. Many studies have documented equivalent or enhanced outcomes when using groupwork (homogeneous and heterogeneous) relative to other modes of instruction along dimensions such as content mastery and prosocial sentiments towards others of different backgrounds (see Cohen, 1994a; Lou et al., 1996; Webb, 1991). The organization of effective groupwork is not trivial. Among other aspects of instruction, teachers need to select appropriate tasks that allow all students access to the mathematics; use instructional strategies that prompt participation by all students; and support high quality mathematics conversations within groups. Not accomplishing any one of these can exclude some students from participating in interactions necessary to support their learning.

Some consistent principles for designing effective groupwork can be derived from the body of research on this topic (Cohen, 1994a). For example, one condition is interdependence among group members. There are different forms of interdependence. Goal interdependence occurs when each group member can achieve his or her goal only when other group members also achieve their goal, for example, creating a group product whose production requires input from all students. Resource interdependence occurs when group members need information or resources from other group members (e.g., a jigsaw situation) to complete their task. Promoting individual and group accountability is another principle that has been shown to be productive for groupwork. Both of these principles promote student-student task-related interaction.

Research regarding other characteristics of groupwork and the relationship to student outcomes is not as definitive. Perhaps this should not be surprising given the complexity of group interactions and classroom systems. In her review, Cohen (1994a) identified several factors that produced mixed results with respect to student engagement or achievement within 
groups. These factors included the level of cooperation (vs. competitiveness) among groups and the specificity of ascribed student roles. Cohen offered some propositions to reconcile the seemingly contradictory findings. She argued that, depending on the type of learning goal, different kinds of interactions are beneficial. For routine problems and mastery of already presented information, Cohen concluded that the availability of good explanations is crucial. Good explanations generally stem from more structured patterns of interaction among group members. In contrast, for ill-structured problems (open-ended, non-routine) and learning goals focused on developing higher-order reasoning and problem solving skills, students needed latitude in their interactions to engage in the generative exchanges required to solve these problems. For such learning goals, "task arrangements and instructions that constrain and routinize interaction will be less productive than arrangements and instructions that foster maximum interaction, mutual exchange, and elaborated discussions" (Cohen, 1994a, p. 20). This led Cohen (1994a) to highlight a core challenge in organizing productive groupwork:

Herein lies the dilemma: If teachers do nothing to structure the level of interaction [among group members], they may well find that students stick to a most concrete mode of interaction. If they do too much to structure the interaction, they may prevent the students from thinking for themselves and thus gaining the benefits of the interaction. (p. 22)

Drawing on Barnes and Todd (1977, as cited in Cohen, 1994a) and others, Cohen elaborates this point indicating that supporting more exploratory and collaborative talk requires the delegation of authority. The teacher cannot directly monitor the groups' ongoing work, as this impedes the very talk that is productive. Yet, promoting higher-order thinking and the engagement of all students, particularly those of lower academic status, requires teacher intervention and direction. 
The teacher must judiciously use her position to enable productive conversations and find a delicate balance between creating structure and opening space for students to collaborate. At first glance, offering structure and affording autonomy may seem contradictory ends, but they need not be. Although structure can be thought of as a constraining factor, structure also creates affordances (Greeno \& MMAP, 1997) for student interactions, sometimes by restricting options.

This analysis of a detracked, geometry class seeks to inform the issue outlined in Cohen's "dilemma". It demonstrates how one teacher fostered collaborative interactions among students as they worked in heterogeneous groups on open-ended problem solving activities. The dilemma Cohen defines precludes simple analysis of cause-and-effect relationships. It requires careful attention to the interconnectedness among various components within the system and an understanding that student collaboration is an emergent practice embedded within a complex system. For these reasons, it was necessary to use a framework that could conceptualize student interactions within groups as an emergent product of the classroom system. Complexity science provided the requisite framework for this task.

\section{Conceptual Framework: Complex Systems}

Complexity science refers to a family of perspectives that are often based on ecological approaches to learning. They take as the unit of analysis not an individual organism or member of a community, but the collective or system as a whole. A main tenet of these perspectives is that a complex system cannot be understood by breaking it down into its individual parts or constituents. Rather, the patterns and practices that result from the interaction among individuals within the system must be understood as emergent. "In effect, a complex system is not just the sum of its parts, but the product of the parts and their interactions" (Davis \& Simmt, 2003, p. 138). 
The idea of emergence, or emergent behaviors, plays a central role in complexity science (Barab et al., 1999). This is a defining feature that sets complex systems apart from simple systems. In simple systems, certain inputs cause/predict certain outputs. In complex systems, there is constant dynamic change, whereby the system adapts and learns. From the constraints or "rules" of the system, patterns of interaction, behaviors, or noticeable regularities emerge, yet there is always opportunity for innovation. In a classroom, a group's practices are emergent and the innovations produce new ways of interacting and novel approaches to problems. A group's behaviors and solution path are not predictable and cannot be prescribed, but they are bounded, and they emerge in relation to the environment.

Drawing on a range of literature, Davis and Simmt (2003) identified five overlapping principles of complex systems: internal diversity, redundancy, decentralized control, organized randomness and neighbor interactions. These principles are "necessary but insufficient conditions [that] must be met in order for systems to arise and maintain their fitness within dynamic contexts - that is, to learn" (p. 147). I describe each principle, attending more to the last three, as they build on the first two and were central to illuminating aspects of the teacher's role in this classroom.

Internal diversity. Internal diversity references the variety of different ways members can contribute. Diversity is a resource for the generation of new practices and solutions. It supports learning and adaptation.

Redundancy. Redundancy enables communication, as group members mutually recognize various cues and meanings of symbols, words and gestures. It provides a level of coherence and a common basis to support communication. A redundant system also does not uniquely rely on 
one component to fulfill a role. Having multiple ways to fulfill the same function makes the system resilient and adaptable.

Decentralized control. Control, or authority, in a mathematics classroom can be exercised with respect to mathematical ideas or with respect to the particulars of the interaction. In many classrooms, the teacher maintains a high degree of authority, particularly with respect to identifying preferred methods and determining correctness of the mathematics. In some classrooms, the teacher also maintains control over the kinds of opportunities individuals have to interact. These can be quite constrained. Decentralized control - or distributed authority - offers students and/or groups the authority to devise approaches and mathematical strategies and to regulate their behaviors (within the constraints of the broader system). It invites a broader range of participation. This principle must be balanced by other principles so that the emergent interactions are generative rather than unproductive.

Organized randomness. Balancing and helping to capitalize on decentralized control and internal diversity is the principle of organized randomness. "The structures that define complex systems [must]... maintain a delicate balance between sufficient organization to orient agents' actions and sufficient randomness to allow for flexible and varied response" (Davis \& Simmt, 2003, p. 155). Thus, particularly when students are working on open-ended or non-routine problems, some level of structure is needed to promote student task-related interaction, perhaps through goal interdependence or other means. Structure orients participants within the system so that their individual efforts or ideas can brought together productively towards some goal or ends. What emerges is patterned or organized.

Neighbor interactions. Neighbor interactions is needed to capitalize on internal diversity. This principle refers to the possibilities of ideas "colliding" with one another, which supports the 
spreading and exchange of ideas for the purposes of innovation. In a classroom, for ideas to collide, students need to share ideas with others and listen to and evaluate the validity of others' ideas. Neighbor interactions can also refer to exchanges between groups and not just within groups.

These principles of complexity science described by Davis and Simmt (2003) offer a way to think about Cohen's dilemma, which calls for a balance of structure and autonomy in governing student-student interactions with respect to mathematical ideas. Too much structure and the group will be overly constrained and not have the autonomy to engage in collaborative, generative interactions. Too little structure, and students' individual contributions and efforts may be too random or diffuse to develop a flow or focus. Davis and Simmt (2003) describe the need for "a shift in thinking about the sorts of constraints that are necessary for generative activity" (p. 155). It is understanding the constraints "necessary for generative activity" that is pursued in this analysis. Given that the teacher cannot prescribe collaborative interactions, I examine ways the teacher promotes the emergence of such interactions within groups.

Data Sources and Methodology

\section{Participants and Context}

The teacher, Linda McClure (all names are pseudonyms), was a white female with three years of teaching experience at Railside School, an urban high school of 2400 students from various ethnic, linguistic and socio-economic groups. The mathematics department had detracked their program in the 1990s in response to low student achievement and racial tensions at the school. Railside School has been identified as being successful in supporting students' mathematics learning (see below). Ms. McClure was recommended as a teacher who promoted high-quality mathematics conversations in her classroom. Like the other teachers in her 
department, she used heterogeneous groupwork almost exclusively as an instructional format. Ms. McClure's geometry class was selected for the study.

The Railside mathematics teachers grounded their pedagogical approach in Cohen's program of complex instruction (Cohen, 1994b; Cohen \& Lotan, 1997). Complex instruction is a form of groupwork originally designed to address the unequal status of different students in classrooms. Cohen's research consistently has found that, for conceptually oriented, high-order tasks, unequal participation among students is linked to variation in learning gains. Unequal participation stems from status differences.

The geometry curriculum was created by Ms. McClure and her colleagues specifically to support groupwork in their heterogeneous classrooms. Evident in the curricular materials was an emphasis on non-routine problems and developing mathematical understandings via problem solving (Schroeder \& Lester, 1989). The curricular tasks were "groupworthy" (see Horn, 2005) which meant that they focused on core mathematical ideas, were characterized by multiple representations and solution paths, and were likely to draw on the various collective resources of a group.

The productiveness of the Railside teaching approach for student mathematics achievement and attitudes has been documented extensively by the Stanford Mathematics Teaching and Learning Study (SMTLS) (Boaler, 2006, in press; Boaler \& Staples, in press). Railside was one of three participating schools. Boaler found that Railside students entered ninth grade performing significantly lower on an assessment of middle school mathematics than students at the other two schools. By the end of the year, however, there were no significant differences between the scores of Railside students and students experiencing other teaching approaches at the other schools on a content-aligned assessment of algebra. This trend - where 
Railside students performed equally well or outperformed the other students -continued for the students' high school careers. In addition, at Railside, differences between the scores of students of different ethnic groups decreased over time.

Although Ms. McClure's $10^{\text {th }}-12^{\text {th }}$ grade geometry students were not part of the SMTLS cohort, which comprised incoming $9^{\text {th }}$-grade students in 2000-2001, data for this case study were collected concurrently and students in this geometry class experienced the same teaching approach and curricular materials as the SMTLS students. Thus, given the documented success of the Railside approach, this geometry classroom provides an important example of productive groupwork in a detracked, heterogeneous mathematics classroom and an opportunity to augment our understanding of how teachers productively organize these learning environments.

The focal geometry class comprised approximately thirty-one $10^{\text {th }}-12^{\text {th }}$-grade students. The population of the class reflected the ethnic diversity of the school which was approximately 20\% Asian, 25\% White, 25\% Black, and 35\% Hispanic/Latino/a (retrieved December, 2000, from www.cde.ca.gov; data have been rounded to the nearest 5\%). During classtime, students were arranged in heterogeneous groups which rotated approximately every two weeks. Classes met daily for one-and-a-half hours for one semester.

\section{Data Collection and Analysis}

Data were collected from multiple sources. I observed 39 lessons during the semester (approximately 58 hours), for which I recorded fieldnotes and wrote up more detailed notes and reflective memos following most lessons. Twenty-six lessons were also videotaped which provided the opportunity to return to the lessons for more detailed analyses. In each lesson, I recorded all whole-class activities and public discussions. During groupwork, I used two strategies: I followed the teacher as she moved from group to group, or I focused on one group. 
In addition, I collected curricular documents and other materials, and I conducted interviews with a majority of students (18 total, in pairs) and with the teacher $(3 \mathrm{x})$. The analysis presented here draws primarily on the video data and fieldnotes.

Data analysis followed standard qualitative techniques. In the first phase of analysis, I used open coding (Glaser \& Strauss, 1967; Strauss \& Corbin, 1998) on fieldnotes, looking for emerging themes in relation to the research questions. These fieldnotes comprised documentation of the lessons (content, tasks, major segments), reflective notes, and records of conversations with Ms. McClure regarding the class and the mathematics program. This analysis was conducted concurrently with the fieldwork, thus providing the opportunity to compare and refine emerging patterns against subsequent classroom events. The result of this process was a preliminary set of themes related to the constraints and affordances the teacher organized to support student collaboration.

In the second phase, ten focal lessons were selected for more detailed analysis. The initial four lessons were chosen because the video recordings had significant periods of time when the camera was focused on a particular group so the students' interactions when the group was not under the direct purview of the teacher could be analyzed, as could the influence of the teacher's interactions with the group when she directly worked with them. Video content logs, which recorded activities at 30-second intervals, were prepared for each lesson and were analyzed in relation to the codes/themes developed in the first phase of analysis to further document how the groups' work together was organized and supported.

The other six videos were chosen to represent lessons early and late in the semester. Segments related to students' collaborative work and the teacher's interactions with groups were transcribed. Building on the identified themes, a graduate research assistant and the author 
prepared an analytic memo for each lesson. These analytic memos were synthesized to produce a final document regarding the teacher's work that supported the group collaboration around mathematics. Two additional videos were selected to review for disconfirming evidence. At the same time, we conducted a parallel analysis on a second high school teacher at another school (Staples \& Colonis, 2006). This second classroom provided a point of contrast and comparison that helped illuminate particular features of Ms. McClure's classroom.

Two forms of triangulation enhanced validity. I conducted a member check, whereby Ms. McClure read an earlier version of this paper. She confirmed that the portrayal of her practice was accurate and she recognized various elements of her practice that I identified as important to her work with groups. I also triangulated the video analysis with information gleaned from interviews.

In the final step, the results were considered in light of the literature on heterogeneous groupwork and complex systems. This led to further refinement of the relationship among categories, as the literature highlighted aspects of the classroom system that were likely critical to the organization of productive groups. The four categories reported in this paper were identifiable elements of the teacher's practice that were connected with the patterns of interactions observed across the groups.

\section{Results}

This analysis focuses on how the teacher fostered collaborative interactions within groups. The groups' ways of interacting can be seen as emergent against the backdrop of the constraints and affordances of the system organized by Ms. McClure. As discussed earlier, for non-routine problems and for the purposes of developing higher-order thinking among students, 
students need to be given latitude and support to explore the mathematics. Four categories emerged as critical for understanding the teacher's role. These categories are the following:

1. Promoting individual and group accountability

2. Promoting positive sentiment among group members

3. Supporting student-student exchanges with tools and resources

4. Supporting student-student mathematical inquiry in direct interaction with groups These four categories are referenced as: 1) the accountability system, 2) positive sentiment, 3) tools and resources, and 4) direct teacher-group interaction. For each category, I describe the relevant aspects of the teacher's work and how these aspects supported a system that prominently shaped the students' interactions during groupwork, especially when the teacher was not present and working directly with the group. This emphasis is appropriate for two reasons. First, the teacher is necessarily constrained in her direct interaction with groups, as her presence is likely to limit the group's collaboration and exploration of mathematics together, as described in Cohen's dilemma. Second, it is a practical impossibility to spend significant amounts of time with groups, as there are multiple groups in the classroom and the teacher must attend to each. Thus, much of the teacher's influence on how students' interact around content is indirect, emerging from the classroom system that is established. The presence of the principles of decentralized control, organized randomness, and neighbor interactions will be apparent in the analysis presented. I return to these principles more explicitly in the discussion section to understand Ms. McClure's role in supporting a system with these conditions.

\section{The Accountability System}

In Ms. McClure's classroom, the accountability system promoted individual and group accountability among students with respect to a) learning mathematics and b) enacting good 
groupwork. Various aspects of this accountability system promoted group interdependence, a critical feature for productive groupwork (Cohen, 1994a). I discuss both the informal (formative) and formal (summative) assessment systems. (Several of the practices described here were used by other teachers in the mathematics department. See Boaler (2006, in press) and Boaler \& Staples (in press) for additional discussion of how Railside mathematics teachers promoted student responsibility and relational equity.)

Accountability system - enacting good groupwork. In all documented lessons (barring those in the computer lab), Ms. McClure used verbal feedback as a mechanism to promote group accountability for enacting good groupwork. She highlighted practices she wanted to see and provided information regarding the degree to which she saw these practices. This feedback was prominent as groups started a new task. Typical comments she made included the following:

"I like how Group 5 is putting the picture in the middle of the table to do the problem. That way everyone can see the pictures."

"Group 8 is reviewing already. Thank you Group 8."

Ms. McClure believed that if she made clear to the students what doing good groupwork was, they would enact those practices. "If I make explicit what is doing well, they'll act it out." Her verbal commentary made salient productive practices. Her naming amplified them and sanctioned them as appropriate. Similarly, at the end of class, Ms. McClure debriefed by recapping the mathematics and commenting on the class's participation that day. Often there was praise for their engagement, persistence, and good mathematical thinking. When appropriate, Ms. McClure commented on how they could improve their work together.

"I loved the work I'm seeing. Many of you are really thinking hard about how to approach the problem and coming up with great ideas. I'm a little concerned 
however that not everyone in the group is together always. Sometimes a group member is being left behind. Groups, be sure everyone understands what's going on. And everyone, be sure you ask questions!"

"You guys are doing fabulous math work in here.... But some times a few groups are starting to visit a little too much.... If you don't stay focused, you will fall behind and get frustrated. You have to govern yourselves."

These comments focused on group processes and the kinds of participation for which groups were responsible. Ms. McClure indicated that she expected groups to monitor and regulate their interactions. In addition, the group collectively was responsible for each member's understanding and each individual was responsible for asking questions.

Group quizzes further promoted productive group processes and interdependence among group members. To conduct a group quiz, Ms. McClure put up a blank overhead and listened to the groups as they worked together. She wrote partial quotes or comments that she heard, indicating the group number, to capture group processes. If Ms. McClure evaluated what she observed positively, she wrote the comment up in one color; if it were evaluated negatively and not seen as productive for groupwork, she wrote it up in another color. At the end of the class, she assigned each group a score based on her recorded observations.

Accountability system - learning mathematics. The accountability systems also promoted interdependence among group members with respect to their mathematics learning. Ms. McClure administered both group tests and individual tests. A group test was given first, and students worked collaboratively to solve the problems. The students had their own paper. Ms. McClure collected all four papers and randomly graded one of them. The mark for this paper was the grade for each group member. A few days later, students took an individual test on the same 
material. It was expected that, in part, the group test would serve as an opportunity to review or solidify each student's understanding of the mathematics.

This assessment system promoted mutual accountability and interdependence among group members as an individual's work on the group test was consequential for the group as a whole. Furthermore, given the upcoming individual test, individuals were likely to use this as an opportunity to ensure they understood the mathematics. Importantly, the length of the test permitted time for discussions. Note that the combination of the group and the individual test, graded in the particular manner described, with the appropriate time allotted, created a system that encouraged collaborative interactions around the mathematics and supported the participation of all students.

Another form of assessment was a content-focused group quiz. As she launched the task, Ms. McClure announced that she would quiz groups on particular problem(s). When the group had completed an indicated problem and felt ready for the quiz, they called over Ms. McClure. Sometimes Ms. McClure chose the member to be quizzed randomly (through shuffling papers); sometimes the speaker was her deliberate choice. The group received points based on this student's response. The student had to explain how the group solved the problem and answer Ms. McClure's follow-up questions. If the student could not satisfactorily respond, Ms. McClure told the group to talk about the problem a little more and then she would return to quiz them again. Sometimes Ms. McClure returned multiple times.

This quizzing practice encouraged student collaboration. Prior to the quiz, groups worked to ensure that all members understood. If unsuccessful on the quiz, Ms. McClure left a group to think about a problem further and then returned to quiz them again. The response of the group was to talk about the mathematics or work with the student(s) who needed more support to fully 
comprehend or articulate their solution. Of central importance was the nature of Ms. McClure's questions. It was these questions to which students were held accountable. These were higherlevel questions that required justification or clear articulation of a concept and related ideas. To successfully respond, students needed to know more than procedures or an instrumental explanation.

It is helpful to contrast this to a classroom system where students are arranged for groupwork but the assessment system is an individual one. In such a case, the student need only have the goal of promoting his own understanding. There is minimal incentive for group members to respond to request for an explanation, initiate an explanation to another even when not requested, or demonstrate a lack of understanding by asking a question. By contrast, in this classroom, the group was accountable for each individual's learning and the individual was responsible to the group for learning. The multiple components of the accountability system created structure for the group's interactions. Ms. McClure did not exercise direct control over the groups, but managed a system that promoted or made likely certain kinds of student-student task-related interactions.

This is not to say that students were always engaged in task-related behaviors. There were times when Ms. McClure needed to reduce a group's classwork points or request that one or more students stay afterschool to discuss their participation with her. Students also did not reach the same level of understanding on each problem. Ms. McClure had to make judgments about how far to push an individual student during a content quiz and what to accept as a sufficient explanation.

\section{Positive Sentiment}


A risk of extensive interdependence is that it can produce intra-group tensions especially if it is perceived that one member is causing the group to not succeed, or if a member feels that another member's suboptimal performance is affecting his grade. If negative sentiments arise through interaction (perhaps because the group is unsuccessful), then the group will be averse to future interactions. Conversely, if group members have positive experiences working together, they will subsequently seek out similar interactions with that group. Positive sentiments can result from a wide range of group activities, such as accomplishing a challenging task, inherently enjoying working together, or being pleased by an 'A' grade. The role of positive sentiments is perhaps particularly important when dealing with open-ended tasks that can occasion situations of frustration for students as they formulate new ideas and press through uncertainty or confusion.

Promoting success. Ms. McClure supported opportunities to develop positive sentiment among group members in a variety of ways. First, although not a focus of this paper, Ms. McClure was quite skillful in selecting and/or designing tasks that were appropriately challenging for students, but that they could complete on some level with reasonable effort. Thus, students had the opportunity to experience success, but this success was the product of effort (see also Horn, 2005). In addition, these tasks could not readily be completed by one student and so drew on the resources of many group members. Consequently, members of a group likely saw their accomplishments as a result of interaction with their group.

Ms. McClure also gave the groups control in deciding when they were ready to demonstrate their understanding on a group quiz. Consequently, there was a high chance that the group would be judged positively. A group presumably would not call Ms. McClure for a quiz 
until they were ready. She made this practice clear the second day of school. She explained that she might ask if they are ready for a quiz:

"But you guys have the option to tell me, 'Wait Ms. McClure, come back in three minutes. We need to review a little more.' And I'll honor that without taking off points. So it's all in your hands."

In addition, Ms. McClure deducted only 1 point out of 10 if the chosen student could not answer the first time and she had to return to quiz the group again. Consequently, a suboptimal initial performance had minimal negative impact on their grade and they still had the opportunity to demonstrate understanding. This approach made likely the group's formal success on the quiz. Note that Ms. McClure did not support success on quizzes by having low standards. She asked questions that probed students' understanding.

This excerpt provides a brief example of how Ms. McClure promoted success (positive sentiment) of the group and the influence of the group's accountability for all members' understanding. The problem was from a warm-up activity where two different (fictitious) people had created formulas for the area of a particular parallelogram (see Figure 1).

$<<$ insert Figure 1 about here >>

The students had to decide which formula was correct and explain how they knew. After the students worked for a few minutes, Ms. McClure began to interact with groups. She approached group 8 and asked if they had a response to share.

Approaching group 8

LM: So, do you guys got it?

B: Ye-up 
LM: Tell me about it ma'am. Specifically addresses Tanesha, indicating that she should be the speaker for the group.

T: OK. You take that and put it over there, it'd be a square, and if you put it, in half, but half she starts laughing

LM: You want me to come back real quick?

T: $\quad$ Yeah laughing

LM: I want everyone to have it. Says as she pats $T$ on the shoulder and starts to move away from group. She's got the right idea. Talk it over with her one more time.

T: I understand, I understand. It's just that I forgot.

LM: But you forgot. OK. Talk with her about it real quick and I'll come back. LM departs. Turns over her shoulder and says to the group Cause you guys are sayin' something cool.

When it seemed that at least one member of the group (Tanesha, a lower-attaining student) did not fully understand the problem yet, Ms. McClure restated that she wanted everyone "to have it." Ms. McClure left the group, explaining that she would come back. Ms. McClure did not identify the initial response as incompetent or wrong, but rather as a work in progress. With more group interaction, Ms. McClure expected everyone in the group would understand.

The idea that not understanding was a transitory state was also conveyed with comments by Ms. McClure such as "not that it's wrong, it's just incomplete." Such comments prompted groups to continue their thinking and build on the work they had already done. When Ms. McClure returned later, the students generally gave an improved response. Her stance towards 
their work and her assessing practices supported group success and the development of positive sentiment. In the above lesson, when Ms. McClure returned to the group, Tanesha provided a more coherent explanation.

Product differentiation. Another critical feature in promoting positive sentiment was that tasks were deliberately designed and implemented to allow for product differentiation, whereby a range of mathematical solutions could be produced and deemed quality work. Particularly given the class's heterogeneity, there was often a variety of solution strategies evincing various levels of sophistication. In general, there was not an identified "endpoint" that each group had to "get". Ms. McClure valued each group's work and positioned each solution as evidence of competence and productive mathematical work.

In the above lesson, after the groups had worked on the problem, Ms. McClure selected three groups to present their solutions at the overhead. Each approach demonstrated a different level of sophistication with respect to proof. The first group showed a "plug in" method, using two sets of numeric values, which produced the same areas for each formula. The second group demonstrated how each formula described the parallelogram's area by mapping components of the formula to the figure. The third group algebraically demonstrated that the two formulas were equivalent (which showed that either both were correct or incorrect). Each approach was valued as productive mathematical work. Ms. McClure also engaged the students in a discussion of what each method did and did not demonstrate and she discussed with them a bit more about what comprised a proof.

Ms. McClure's approach avoided direct comparison among groups -where one group might feel they "get it" and another feels inadequate. At the same time, Ms. McClure upheld disciplinary standards for what counted as quality work and what was a more or less 
sophisticated response. For example, the following excerpt is from an interaction with a group that used the "plug in" strategy for the parallelogram problem. Ms. McClure accepted their response as reasonable and productive, but then pushed them to think about the limitations of the approach:

LM: But what if it's 10, 2, and 7?

D: inaudible

LM: How do you know? You'd have to plug it in, right? What if it's 14, 6, and 3 ?

B: Plug it in.

LM: So basically for every single parallelogram, to prove it, you'd have to plug it in. And how long would that take? Like forever right? So is there any way you can convince me. I mean, plugging in numbers is a great idea 'cause it's testing if it works, but how could you convince me for every single parallelogram. Say I'm a total skeptic and I don't believe you guys, like I make you prove to me over and over again.

LM: See if you can come up with a way to convince me without plugging in all the time. Because plugging in would take too long. It would work, but it would take too long.

This excerpt demonstrates how Ms. McClure gave groups autonomy (decentralized control) in generating solutions, but also pressed them toward increased sophistication in their 
mathematical reasoning. Here, she positively evaluates the group's strategy, but also pushes them to think of another method after pointing out a limitation of their approach.

Ms. McClure's approach likely played an important role in promoting positive sentiment as each group could experience success. Furthermore, requiring more homogeneity with group products- or guiding students towards one endpoint - would affect the nature of the studentstudent interaction within the groups. Guiding students towards a particular method can constrain their talk (and thinking) and place unwarranted value on one particular method over others. If students see their ideas as "not what the teacher wants," they are less inclined to engage with the problem and see themselves as producers of mathematical ideas. In addition, guiding students to a particular solution can undermine the development of positive sentiment, as students might not see their solution as a product of their group's thinking.

Enthusiasm for student thinking. A final way Ms. McClure promoted positive sentiment was by expressing genuine enthusiasm for the ideas that a group generated. In the excerpts above, she talks about students' ideas as "cool" and notes that "plugging in is a great idea". In general, she expressed intrigue in their formulations and positively reinforced strong efforts and good thinking even when the problem did not fully yield to the group. The group's effort and mathematical thinking were valued highly. Along this dimension, all groups had the opportunity to be successful.

Praise, in the form of rewards and evaluative judgments, has been shown to potentially undermine students' learning by affecting their goals and motivation (e.g., Dweck \& Legget, 1988; Elliott \& Dweck, 1988). Ms. McClure did not express reservations about her praise of students' and groups' thinking. She felt it was important for students to feel that she valued their thinking and that they were capable producers of mathematical ideas. The long-term effects of 
these practices are not clear. Boaler's research, however, found that Railside students enjoyed mathematics more, indicated more agency and authority with respect to the discipline, and reported an intension to pursue mathematics in college at higher rates than students at two other schools (Boaler, in press; Boaler \& Staples, in press). This potentially suggests the need to understand any one assessment or feedback practice as a component of a larger system.

Group members' positive sentiment towards one another has an indirect, but potentially very significant, impact on the nature and quality of group interactions. Such sentiments prompt interactions that are above and beyond the "letter of the law" in the classroom. Group members are more likely to extend an important conversation or persist on a challenging problem (Forsyth, 1999) having found the group success in its prior collaborative work. From a complex system perspective, where the system is always adapting and evolving, these developing relationships can be understood as feedback loops. Some feedback loops have a dampening effect, whereas positive feedback loops can have an amplifying effect, enhancing subsequent activities in a particular direction.

\section{Tools and Resources}

Tools are practices or objects (physical or conceptual) that a group can use to accomplish its work together (Wenger, 1998). The particular tools available, including those tools whose use is required, create a set of constraints and affordances that shape a group's interactions. They are resources that can be used to support a group's work. In this section, I focus on two tools and resources that figured prominently into a group's work together: the physical space and group roles. These tools were deliberately brought into the groups' work environment by Ms. McClure. She strongly encouraged and reinforced their use. This was another means by which Ms. McClure promoted student collaboration. 
Structuring the physical environment. Ms. McClure structured the physical environment to make it conducive for groupwork. The classroom desks were arranged in groups of four or five. When introducing a new activity, Ms. McClure asked groups to clear their "table" of all backpacks, books, etc., for example, "I want you to have lots of space because you will have to talk in the middle." This practice set up a common work area accessible to all group members.

This phrase "in the middle" was used repeatedly by Ms. McClure. It focused students on the physical space in the middle of their desks where they should work together on the mathematics. After handing out the problem, Ms. McClure would often go around and put scrap paper in the middle. This act helped to orient students, moving them away from the mindset of an individual working at her own desk to the group working on the problem in the middle where their ideas could be represented and shared. Ms. McClure also reinforced this idea during lessons. In this excerpt from the same lesson, one student, Paj, has just offered an incomplete explanation.

LM: But why do they both work? Danesha, did he convince you that they both work? P: They're the same thing, just put in different words.

LM: Could you show your group members that they are the same thing, but put into different words?

P: (inaudible)

LM: Oh, puh-lease. Maybe you have to try defining better. You know, that's why you have this big piece of paper in the middle, so you can talk about it. And when you can convince them, I want to hear it. She leaves the group.

In addition to demonstrating Ms. McClure's emphasis of the space in the middle, this excerpt shows how Ms. McClure maintained the interdependent task goal that all students understand. 
Another way Ms. McClure created common physical focal points within the workspace was by handing out only two assignment sheets per group. This made it more difficult for students to work on their own. She also frequently had one of the two sheets in a plastic slip cover. Although she told students that she needed the papers again the next year, so she wanted only one written on, Ms. McClure explained to me that she generally modified them slightly so the plastic slip cover served primarily as an excuse to focus group members on one or two papers and encourage them to talk together. Ms. McClure's organization of their physical environment made certain behaviors and interactions more likely. It limited the students' ability to work individually and made readily available a collective workspace.

Student roles. Assigning student roles is a standard strategy for supporting the work of a cooperative group (Cohen, 1994b). The roles used in Ms. McClure's classroom were adapted from complex instruction (Cohen \& Lotan, 1997): team captain, materials manager, reporter/recorder, and facilitator. These social roles had ramifications on the nature of the group's interactions. Depending on the exact task, Ms. McClure varied the specific responsibilities for the role. In general, the team captain kept the group on task; the materials manager retrieved and returned necessary supplies; the reporter/recorder kept track of the group's ideas and raised his or her hand to ask group questions; and the facilitator made sure all voices were heard and checked for understanding.

In this excerpt, Ms. McClure restated the roles and indicated specifically how those roles would play out as they discussed the homework problems due that class period.

And of course you're going to use your roles. Team captain, you're going to be sure that there's no direct copying. If I see direct copying, those papers go away. Zero points. Facilitator, you're going to make sure that all the answers are compared. That 
could be reading out loud, that could be papers in the middle. ... Materials manager, you have the most important job. Your job is to make sure that all discussions happen in the middle of the table if there's a question. So suppose that in this group, (inaudible) got one answer and Michael got something totally different, it's the materials manager responsibility to make sure that gets discussed and that everyone agrees in the end. And lastly, recorder/reporter, you're going to keep track of time. So if I say 2 minutes, you're going to make sure your group is ready in 2 minutes. And you're also going to tell me the questions your group absolutely has to see on the board. Once again, you don't have a question unless the whole group is stuck. Otherwise you can say, "no question, we get it." Any questions on how to do this?

These roles, as implemented, shaped how each group carried out its collective work together. From my analyses, the role (and role procedures) most significant to the group's interactions with respect to mathematical collaboration was materials manager. The materials manager was responsible for raising her hand to ask any "group questions." A group question is a question the entire group has: everyone in the group is aware of the question and no one can answer it. Ms. McClure regularly noted that she would entertain only group questions. She was consistent in enforcing this practice, although there were a few occasions when this was not strictly followed. When Ms. McClure responded to the materials manager's raised hand, she often asked the group "Is it a group question?" or she asked someone other than the materials manager what the question was. If the person Ms. McClure asked could not state the question, or if the group indicated that they did not know if it was a group question, she departed commenting that they could call her back when they had a group question. 
This technique was effective in helping to structure student-student interaction and group collaboration because it made necessary exchanges around a specific issue prior to asking the Ms. McClure. For example, during one lesson a group of students was working on a warm-up problem. Three of the group members were working well together, and two boys seemed to be a little more on the fringes. These boys were English language learners which may have contributed to their observed level of group involvement. One group member identified a question as a group question and prompted the materials manager to raise her hand. As the materials manager raised her hand, another group member asked the two boys if they had heard the question, which would be necessary to have Ms. McClure talk with them about it. They responded no. The question was repeated for them. Hearing the question, one of the boys answered and the group continued on with its work after a little more discussion about that point. This interaction emerged within the context of the system that Ms. McClure established. Apparent in this example are elements organized randomness (orienting) and neighbor interactions in support of student collaboration.

\section{Teacher-Group Interaction}

This analysis has focused on how student-student interactions within their groups are influenced by the characteristics of the systems Ms. McClure established, particularly when Ms. McClure was not directly working with the group. For example, although Ms. McClure reinforced the idea of working in the middle when she directly interacted with groups (as in the example with Paj above), equally important was the influence of this move in shaping the group's interactions when she was not present and directly monitoring their activities. As part of this fourth category, teacher-group interaction, I describe how particular choices Ms. McClure made when directly interacting with groups around mathematical ideas kept authority and 
responsibility for thinking with the students and encouraged productive student-student interactions both during the interaction and when Ms. McClure was subsequently not present.

One noticeable feature of Ms. McClure's interactions with groups was her choice of when to leave a group. Ms. McClure generally first listened to understand what the group was thinking. Next, as appropriate, she helped them gain more clarity on their point of confusion or focused their attention on an aspect of their logic that was incomplete. Then she would leave them to continue their work as a group.

For example, in one lesson, students were working to prove (or disprove) the following statement: the quadrilateral created by bisecting the angles of a parallelogram is always a rectangle. One group correctly explained to Ms. McClure that a set of four congruent angles was created by bisecting opposite angles of the parallelogram, but they made some assumptions in claiming that opposite sides of the new quadrilateral were then parallel. They had referenced alternate interior angles as part of their explanation. Ms. McClure responded to their explanation.

LM: You've proven that [the two pairs of angles are congruent] to me, but your argument for why those lines have to be parallel, I am feeling a little lost on.

$\mathrm{S} 1:$ Well also, so this, so this is aa, (he points to one of the angles created by a bisector) and this is aa, and when you (inaudible) do it the same kind of thing. ...

S3: Because, because they're the same angles, like over here to over there (points). Because it's the same angle, it's going to set these lines the same angle apart.

LM: So, if you can show to me that they are alternate interior angles, then lines are parallel, then that's cool. If you can show me that they are corresponding angles and they're equal, then the lines are parallel. So, you guys are definitely on the right 
track, but you're going to need a few more angles to be able to say that they're parallel. So look for them. You guys are definitely on the right track.

\section{LM leaves group. Group continues discussion.}

S2: Pointing to a figure in the middle of the desks You see this triangle right here and this one? Then there's this one in here without this line and then there's this one in here without this line. ...

In this brief segment, as is typical of many interactions with groups, Ms. McClure listened to the group's argument, identified a place that needed further elaboration, listened to students' initial responses (in part to be sure they understood what she was raising to their attention; in this case S3 offers a reasonable, but informal argument), and then indicated an aspect of their thinking they needed to continue to pursue to support their argument. As in this excerpt, Ms. McClure often included a statement that provided some encouragement or demonstrated her excitement for their thinking. Note that Ms. McClure did not remain with the group to help construct the needed justification. This work was for the group to do without her. With this approach, Ms. McClure supported the group in moving beyond their current position, gave them responsibility for generating the ideas, and allowed them to continue the conversation unconstrained by her presence. The duration of this interaction was also important because there were eight groups in the room, so it was necessary for Ms. McClure to manage her time to get to all the groups. Even with her concise interactions with groups, groups often had to wait for her attention.

Another important feature, already noted above, was that Ms. McClure's manner of interacting with each group respected each group's intellectual journey. She did not impose a particular method, and only rarely suggested approaches she thought would be easier or more efficient. Her feedback was primarily in terms of responding to and extending their thinking. In 
cases where a group did not have an idea even several minutes into class, she would at first let them think and not interfere. She felt that this was important to reinforce that it was the group's responsibility for thinking and generating some ideas. When groups were not making progress for a significant period of time, Ms. McClure engaged the group to see if she could draw out or prompt some generative discussion, and was at times a little more directive in moving them towards a particular path of problem solving.

\section{Discussion}

I have presented an analysis of one teacher's organization of collaborative groupwork in a geometry class in a detracked mathematics program by examining four aspects of her role: the accountability system, positive sentiment, tools and resources, and teacher-group interaction. The analysis focused on how the teacher organized a classroom system that supported collaborative interaction among students as they worked in heterogeneous groups on open-ended, non-routine tasks. It offers some insights into how teachers might address the dilemma stated by Cohen, whereby teachers must carefully create some structure to support student collaboration, but not overly constrain interactions, as students need autonomy to productively work on non-routine problem solving tasks. This analysis emphasized the classroom as a system with interrelated components that provided a set of constraints and affordances for student interaction.

\section{Complex Systems}

Returning to key principles of complexity science, we can see how the system created by Ms. McClure can be characterized by decentralized control, organized randomness and neighbor interactions.

Decentralized control, with respect to generating mathematical ideas and, perhaps to a lesser degree, group processes, was supported in a variety of ways. Groups generated their own 
paths towards problem solving and were not required to use a particular approach or produce a solution at a given level of sophistication. By strategically choosing when to leave the group (usually after she helped them identify a line of thinking that they could continue to pursue), Ms. McClure kept the group developing their mathematical ideas. In terms of process, groups chose when they would be quizzed and Ms. McClure interacted with groups generally only with their permission (offering them uninterrupted space to think) or under certain conditions. Although students had assigned roles, these were not script like, and all members had the opportunity and responsibility to contribute ideas.

Decentralized control, however, can lead to a lack of productivity or quality thinking if there is no coordination of individual efforts. Complementing decentralized control were elements that promoted organized randomness. To help structure and capitalize on the range of contributions students might make, Ms. McClure made the expectations for group processes very clear and reinforced and supported them through verbal feedback, her interactions with the group, and the assessment system. Each group member was held accountable for explaining the group's solutions and articulating the group's questions which required coordination and communication among group members. Ms. McClure's interactions with the groups and questions she asked them also helped focus their collective efforts, offering them feedback on their mathematical thinking and logic as they developed their solution. Furthermore, group unit tests and group quizzes created a collective goal and promoted interdependence.

For the purposes of prompting collaboration on non-routine tasks, part of organizing randomness is also promoting the colliding of ideas, or neighboring interactions. Many of the above mentioned strategies promoted neighbor interactions and the exchange of ideas. In addition, the use of the workspace and scrap paper "in the middle" helped make public individual 
ideas for group consideration. The positive sentiment fostered within groups further strengthened neighbor interactions among group members.

In Ms. McClure's classroom, although groups were given autonomy in their thinking and many aspects of their group interaction, there was a large number of rules and structures that influenced the groups' activities. One view of these rules and structures is that they are constraints that limited students' interactions in some ways. An alternate view is that these constraints were affordances that were generative for the groups' work together. Thus, constraints are not to control or restrict as much as they are to organize the potentially unconnected contributions and enable a certain set of possibilities for interaction. This reconceptualization of the role of constraints or rules might represent a fundamental departure from how teachers often think about their classrooms and the choices they make in an effort to promote students' mathematics learning.

It is important to recognize that one aspect of this classroom system did not undermine other aspects of it. For example, each group was expected to develop an approach to solving a problem and there was no expectation that the groups would use the same method, learn a "best" method, or complete the same amount of work. Any of these expectations could have undermined the groups' collaboration and the commitment to all students understanding. From a complex systems perspective, such homogenization of approaches or products would undermine the principle of decentralized control (regarding intellectual ideas) and would reduce the meaningfulness of, and the need for, neighbor interactions. Similarly, the assessment system and the ways Ms. McClure interacted with groups consistently oriented them towards exchanging ideas and reinforced group members' mutually responsibility for understanding one another's 
ideas and answering each other's questions. A solely individual assessment system would have been at best neutral towards students' collaborative efforts.

Ms. McClure's teaching of this geometry class seems to represent a successful case of addressing the dilemma posed by Cohen. Cohen highlighted the challenge of identifying a productive level of structure for student collaboration: too much structure and students will not think for themselves; too little structure and students may only think in the most concrete terms. Reframed, the challenge is to find a judicious balance between decentralized control and organized randomness. There is a tendency to want to prescribe-to offer to students an efficient method or to specify how they should talk with one another. However, it is not possible to prescribe collaborative interactions or students' intellectual engagement with a problem solving activity. These practices must emerge - and they emerge against (or in conjunction with) the properties of the complex system. The role of the teacher then shifts: "a key element in effective teaching is not maintaining control over ideas and correctness, but the capacity to disperse control" (Davis \& Simmt, 2003, p. 153). It is the group that ultimately identifies the specific mathematics and mathematical ideas they will work on, where they can more fluidly revisit and connect the diverse contributions, and address gaps in understanding as needed. Ms. McClure's practice seemed to strike a balance whereby groups were provided latitude to collaborative and govern their problem solving process and yet were held accountable to high quality thinking and adhering to certain group processes.

\section{Complex Systems and Implications for Teacher Education}

It is daunting to determine how to offer effective instruction when faced with attending to the range of needs of thirty students. Our typical models for teaching - particularly in mathematics - assume a level of homogeneity across students and are organized around specific 
daily learning goals. Diversity (of student thinking, dispositions, etc., or of learning goals) disrupts this model. Minimizing diversity seems to lead to greater efficiency as fewer approaches are needed, or the response to a given approach is less variable. These models are based more on cause-and-effect relationships between what the teacher does and what the students learn. They do not explicitly account for the fact that students exercise a high degree of agency with respect to their participation in any given setting.

The shortcomings of this model are apparent when one poses the question "How do you teach problem solving?" or "How do you get all students to participate?" These defy cause-andeffect analysis. Indeed, everyday classroom life often defies such analysis, as teachers throw up their hands wondering why something that worked one day does not another. To understand teaching, we must think about how students are participating in the classroom. Thus, we must consider the full complement of actions, tools and resources, accountability systems, etc., the teacher utilizes to establish a classroom system that supports these forms of participation.

Future and current teachers would profit from understanding and being able to analyze the classroom as a complex system, where multiple components mutually influence one another to produce some emergent patterns and structures. On the most basic level, when analyzing a lesson or students' participation, it is important for teachers to consider the interrelated set of factors that supported and undermined the desired outcomes. While potentially useful for all aspect of teaching, using a complex systems perspective may be particularly important or beneficial for specific aspects of the teacher's work such as supporting student collaboration (as discussed in this paper), establishing norms for a productive learning environment, or promoting other less routine kinds of thinking, such as modeling and adapting procedures. 
Take for example the establishment of norms. This teacher task can be conceptualized fairly simplistically, where the teacher states expectations and then positively reinforces the behaviors when they arise and discourages any breaches of the stated expectations. (This may seem to work in some settings.) A complex systems perspective, by contrast, implores teachers to consider how the broader classroom system is making it more or less likely that the desired ways of interacting may emerge. Teachers must ask questions like: What resources are available to students so they can act in ways consistent with the stated expectations? Are there incentives or disincentives, structural or otherwise, that promote or impede such ways of interacting? How is the assessment system, nature of the tasks, or any other component of the classroom influencing a system that supports these norms? Are there components that are undermining the desired outcomes?

Conceptualizing a classroom as complex system foregrounds different resources and aspects of the environment. Complex systems thrive on diversity - it is the grist for the mill. The teacher does not play a gatekeeper role, restricting passage until she deems it appropriate. Her role is gate opener, encouraging all students to be drawn into the process through her interactions with groups and the systems she establishes and continues to monitor and shape over time. The teacher's goal then is to determine the productive constraints and affordances to prompt the emergence of the desired generative activities at the individual and group level.

Supporting teachers in reconceptualizing their classrooms as complex systems, and pursuing the kinds of questions posed above, might lead to habitual ways of teacher thinking that account for the larger system and do not try to reduce explanations about classroom occurrences to more simplistic relationships. Although perhaps foreign to the ways they currently think about teaching, teachers likely have some familiarity with these models, as they have previous 
exposure to thinking about our global environment and smaller ecosystems and how different activities within those ecosystems can have far-reaching or unintended effects as components of the system interact.

\section{Conclusions}

This case provides an important example of teaching in a heterogeneous mathematics class, and begins to unpack the role of the teacher in organizing a classroom system that supports productive student collaboration. Further research is needed to better understand other aspects of the teacher's role and their relation to the emergent patterns of group interaction in, for example, how the teacher promotes more equal participation among group members. Future research is also needed to better understand the degree to which classrooms can be understood as complex systems and how such a framework can be usefully used by teachers to support their thinking, planning and decision making in relation to the classroom. In addition, although achievement and student attitude data were collected from this school and demonstrated significantly more positive results than at comparison schools, future studies might collect such data directly on the class under study to provide further insights into the relationship between students' participation and a variety of outcomes. 


\section{References}

Barab, S. A., Cherkes-Julkowski, M., Swenson, R., Garrett, S., Shaw, R. E., \& Young, M. (1999). Principles of self-organization: Learning as participation in autocatakinetic systems. The Journal of the Learning Sciences, 8(3\&4), 349-390.

Ball, D., \& Bass, H. (2000). Using mathematics in practice: What does it take to help students work collectively? Paper presented at the annual meeting of the American Educational Research Association, New Orleans, LA.

Boaler, J. (2002). Experiencing school mathematics: Traditional and reform approaches to teaching and their impact on student learning. (Revised and expanded edition.) Mahwah, NJ: Lawrence Erlbaum Associates.

Boaler, J. (2006). How a detracked mathematics approach promoted respect, responsibility, and high achievement. Theory into Practice, 45(1), 40-46.

Boaler, J. (in press). Promoting 'relational equity' and high mathematics achievement through an innovative mixed ability approach. British Educational Research Journal.

Boaler, J., \& Staples, M. (in press). Creating mathematical futures through an equitable teaching approach: The case of Railside School. Teachers College Record, 110(3).

Burris, C. C., Heubert, J., \& Levin, H. (2006). Accelerating mathematics achievement using heterogeneous grouping. American Educational Research Journal, 43(1), 105-126.

Carey, N., Farris, E., \& Carpenter, J. (1994). Curricular differentiation in public high schools (NCES 95-360). U.S. Department of Education, National Center for Education Statistics.

Cohen, E. (1994a). Restructuring the classroom: Conditions for productive small groups. Review of Educational Research, 64(1), 1-35.

Cohen, E. (1994b). Designing groupwork: Strategies for the heterogeneous classroom. New York: Teachers College Press.

Cohen, E. (1997). Equity in heterogeneous classrooms: A challenges for teachers and sociologists. In E. Cohen \& R. Lotan (Eds.), Working for equity in heterogeneous classrooms: Sociological theory in practice, (pp. 3-14). New York: Teachers College Press.

Cohen, E., \& Lotan, R. (1997). Working for equity in heterogeneous classrooms: Sociological theory in practice. New York: Teachers College Press.

Cohen, E. G., Brody, C. M., \& Sapon-Shevin, M. (2004). Teaching cooperative learning: The challenge for teacher education. Albany, NY: State University of New York Press.

Davis, B., \& Simmt, E. (2003). Understanding learning systems: Mathematics education and complexity science. Journal for Research in Mathematics Education, 34(2), 137-167.

Dweck, C. S., \& Leggett, E. (1988). A social cognitive approach to motivation and personality. Psychological Review, 95, 256-273.

Elliott, E. S., \& Dweck, C. S. (1988). Goal: An approach to motivation and achievement. Journal of Personality and Social Psychology, 54, 5-12.

Forsyth, D. (1999). Group dynamics. Boston, MA: Brooks/Cole 
Gamoran, A. (1993). Alternative uses of ability grouping in secondary schools: Can we bring high quality instruction to low-ability classes? American Journal of Education, 102, 1-22.

Glaser, B. G., \& Strauss, A. L. (1967). The discovery of grounded theory: Strategies for qualitative research. London: Weidenfeld \& Nicholson.

Greeno, J., \& MMAP (1997). Theories and practices of thinking and learning to think. American Journal of Education, 106, 85-126.

Guitiérrez, R. (1996). Practices, beliefs and cultures of high school mathematics departments: Understanding their influence on student advancement. Journal of Curriculum Studies, 28(5), 495-529

Horn, I. (2005). Learning on the job: A situated account of teacher learning in two high school mathematics departments. Cognition \& Instruction, 23(2), 207-236.

Linchevski, L., \& Kutscher, B. (1998). Tell me with whom you're learning, and I'll tell you how much you've learned: Mixed-ability versus same-ability grouping in mathematics. Journal for Research in Mathematics Education, 29(5), 533-554.

Lou, Y., Abrami, P., Spence, J., Poulsen, C., Chambers, B. \& d'Apollonia, S. (1996). Withinclass grouping: A meta-analysis. Review of Educational Research, 66(4), 423-458.

National Council of Teachers of Mathematics (1989). Curriculum and evaluation standards for school mathematics. Reston, VA: NCTM.

National Council of Teachers of Mathematics (1991). Professional standards for teaching mathematics. Reston, VA: NCTM.

National Council of Teachers of Mathematics (2000). Principles and standards for school mathematics. Reston, VA: NCTM.

National Research Council. (2001). Adding it up: Helping children learn mathematics. Mathematics Learning Study Committee. J. Kilpatrick, J. Swafford, \& B. Findell, (Eds.). Division of Behavioral and Social Sciences and Education. Washington, DC: National Academy Press.

Oakes, J. (1985). Keeping track: How schools structure inequality. New Haven, CT: Yale University Press.

Oakes, J. (1990). Multiplying inequalities: The effects of face, social class and tracking on opportunities to learn mathematics and science. Santa Monica, CA: RAND.

Perry, S. M. (2007). Shaping self-concepts: Ability grouping and middle school students. Unpublished doctoral dissertation. Stanford University, Stanford, CA.

Schwartz, D. (1999). The productive agency that drives collaborative learning. In P. Dillenbourg (Ed.), Collaborative learning: Cognitive and computational approaches (pp. 197-218). New York: Pergamon.

Schroeder, T., \& Lester, F. (1989). Developing understanding in mathematics via problem solving. In P. Trafton \& A. Shulte (Eds.), New directions for elementary school mathematics (pp. 31 -42). Reston, VA: National Council of Teachers of Mathematics.

Staples, M., \& Colonis, M. (2006). Sustaining Mathematical Discussions: A Comparative Analysis of Two Secondary Mathematics Teachers. Paper presentation at the annual 
meeting of the American Education Research Association Annual Conference, San Francisco, CA.

Strauss, A., \& Corbin, J. (1998). Basics of qualitative research: Techniques and procedures for developing grounded theory. Thousand Oaks, CA: Sage Publications, Inc.

Webb, N. (1991). Task-related verbal interaction and mathematics learning in small groups. Journal of Research in Mathematics Education, 22, 366-389.

Wenger, E. (1998). Communities of practice: Learning, meaning, and identity. Cambridge: Cambridge University Press. 


\begin{abstract}
Author's Note
I would like to thank Melissa Gresalfi for her insightful and generative feedback on earlier drafts of this manuscript. I would also like to thank Jo Boaler for her guidance in the design of this project. Finally, I extend my deep appreciation to Linda McClure and her geometry class for allowing me to be a part of their classroom community.
\end{abstract}


Please take out your materials:

Organize binder. Graph paper. Pencil. Calculator

Materials Manager: Scratch Paper

Discuss the following. Use the scratch paper in the middle for discussion notes.

Show the final work on your own paper.

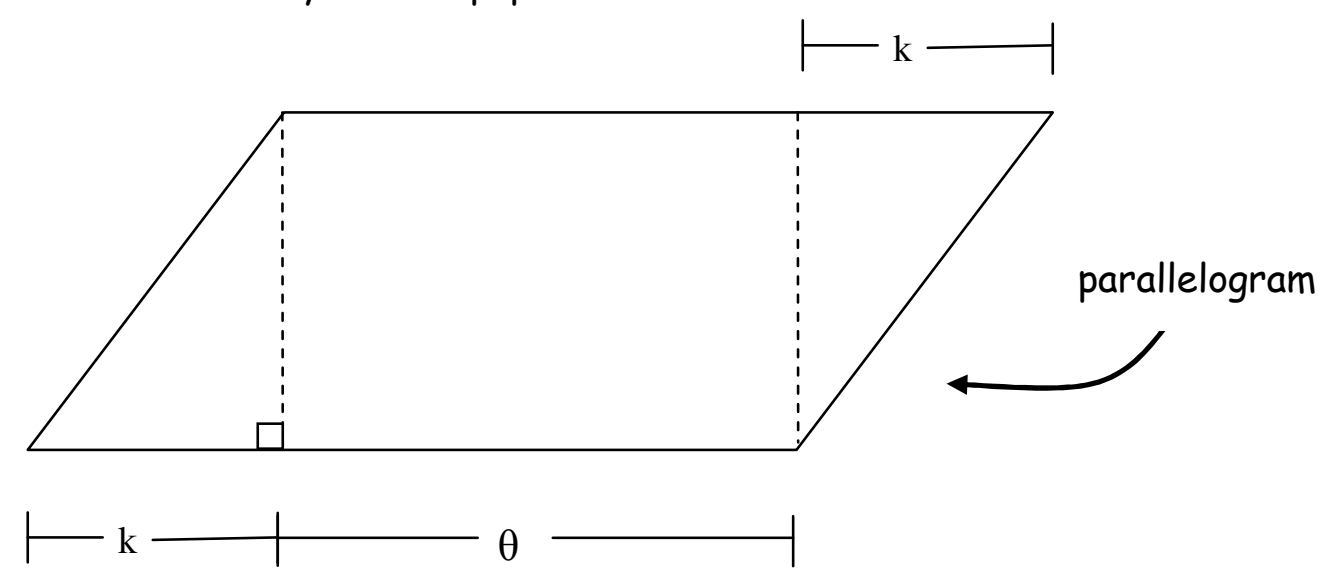

Elizabeth found the area by using

$$
\frac{1}{2} k h+h \theta+\frac{1}{2} k h
$$

Marisol used $h(k+\theta)$

Who did it correctly?

If they are the same, show how you know.

Figure 1. Warm-up problem and overhead instructions. 